\title{
Reference values of interrupter respiratory resistance in healthy preschool white children
} E Lombardi, P D Sly, G Concutelli, E Novembre, G Veneruso, G Frongia, R Bernardini,
A Vierucci
Paediatric Allergy and Pulmonology Centre, "Anna Meyer" Children's Hospital, Department of

Paediatrics, University of Florence, 50132

Florence, Italy

E Lombardi

G Concutelli

E Novembre

G Veneruso

G Frongia

R Bernardini

A Vierucci

TVW Telethon Institute for Child Health Research and Centre for Child Health Research, University of Western

Australia, Perth, Australia

P D Sly

Partially presented at the 1998 European Respiratory Society Meeting, Geneva, Switzerland and the 1999 American Thoracic Society Meeting, San Diego, CA, USA

Correspondence to: Dr E Lombardi e.lombardi@meyer.it

Received 15 September 2000 Returned to authors 4 January 2001

Revised version received

6 June 2001

Accepted for publication

6 June 2001

\begin{abstract}
Background-Interrupter respiratory resistance (Rint) is reported to be useful in evaluating lung function in poorly collaborating patients. However, no reference values are available from large samples of preschool children using the standard interrupter method. The aim of this study was to define reference Rint values in a population of healthy preschool children. Methods-Rint was assessed without supporting the cheeks in children with no history of wheeze from six kindergartens. To evaluate the effects of upper airway compliance on Rint in healthy children, an additional group of preschool children with either no history of wheeze or no respiratory symptoms at the time of testing underwent Rint measurements in our lung function laboratory with and without supporting the cheeks. Short term (about 1 minute apart) and long term (mean 2.5 months apart) repeatability of Rint measurements (2 SDs of the mean paired difference between measurements) was also assessed in children referred for cough or wheeze.
\end{abstract}

Results-A total of 284 healthy white children (age range 3.0-6.4 years) were evaluated. Mean inspiratory and expiratory Rint (RintI and Rinte) did not differ significantly in boys and girls. Age, height, and weight showed a significant inverse correlation with both RintI and Rinte in the univariate analysis with linear regression. Multiple regression with age, height, and weight as the independent variables showed that all three variables were significantly and independently correlated with RintI, whereas only height was significantly and independently correlated with Rinte. Supporting the cheeks had no significant effect on RintI $(n=29$, median $0.673 v 0.660 \mathrm{kPa} / \mathrm{l} . \mathrm{s}, \mathrm{p}=0.098)$ or Rinte (n=39, median $0.702 v 0.713 \mathrm{kPa} / 1 . \mathrm{s}$, $\mathrm{p}=0.126)$. Short term repeatability was $0.202 \mathrm{kPa} / 1 . \mathrm{s}$ for RintI $(\mathrm{n}=50)$ and $0.242 \mathrm{kPa} / 1 . s$ for Rinte $(\mathrm{n}=69)$. Long term repeatability was $0.208 \mathrm{kPa} / 1$.s for RintE $(\mathrm{n}=26)$.

Conclusions-We have reported reference Rint values in preschool white children and have demonstrated the usefulness of this technique in assessing lung function in this age group.

(Thorax 2001;56:691-695)

Keywords: interrupter respiratory resistance; reference values; preschool children
Assessment of lung function in preschool children is difficult. Techniques which require active patient cooperation are difficult to perform and frequently give unreliable results. ${ }^{12}$ Both forced oscillation and interrupter techniques have the potential to provide useful information about lung function in this age group as neither require active patient cooperation. ${ }^{1-7}$ The interrupter technique also has the potential advantage of not requiring complex equipment. Recent technical advances have resulted in the production of a portable system consisting of a rapid shutter and transducer to measure flow and pressure at the airway opening.

Although reference values have been assessed with the opening interrupter method in adults $^{89}$ and children, ${ }^{7}$ no reference values are available from large samples of preschool children using the classical interrupter technique. The aim of this study was therefore to define reference values for interrupter respiratory resistance (Rint) in a population of healthy preschool children using the classical interrupter technique.

\section{Methods}

SUBJECTS

This investigation was performed during the period from spring 1994 to autumn 1995. Informed consent forms and questionnaires about the children's respiratory symptoms were distributed to the parents of all children registered in six randomly selected kindergartens in Florence. A positive history of wheezing was assessed with the questions: "Has your child ever wheezed in the past?", "How many attacks of wheezing has your child had during the past 12 months?", and "Has your child ever used drugs for wheezing?". Children whose parents answered positively to at least one of these questions were excluded from the study. Information was also obtained about the smoking habit of parents or relatives living with the children and the history of asthma of first degree relatives. Since most of the children were white, nonwhite children were excluded from the analysis.

INTERRUPTER RESISTANCE MEASUREMENTS

The portable interrupter device Microlab 4000 (Micro Medical Ltd, Rochester, UK) was used for measuring Rint in the kindergartens. Children were asked to wear a noseclip and breathe quietly through a cardboard mouthpiece $(2.0 \mathrm{~cm}$ diameter). All measurements were carried out with the children standing with the neck slightly extended; the cheeks and pharynx were not supported during the measurements. During tidal breathing, a shutter closed automatically within $10 \mathrm{~ms}$ after peak inspiratory or 
expiratory flow and stayed closed for $100 \mathrm{~ms}$. Mouth pressure was estimated by linear backextrapolation of the post-occlusion signal (at 70 and $30 \mathrm{~ms}$ after closure) to $15 \mathrm{~ms}$ after closure. Rint was calculated by dividing mouth pressure by flow at the time of occlusion. Rint measurements whose pressure-time curves were not of consistent shape (as previously described ${ }^{1}{ }^{10}{ }^{11}$ ) were discarded. Inspiratory (RintI) and expiratory (RintE) resistances were measured in random sequence and were calculated as the mean value of at least six sequentially obtained technically satisfactory measurements during inspiration and expiration, respectively.

EFFECT OF UPPER AIRWAY COMPLIANCE ON RINT MEASUREMENTS IN HEALTHY CHILDREN

To evaluate the effects of upper airway compliance on Rint in healthy children, a further group of preschool children with either no history of wheeze or no respiratory symptoms at the time of the test underwent Rint measurements in our lung function laboratory with the Microlab 4000. For every child, half the measurements were taken with the parents supporting their children's cheeks with their hands in a random sequence. Rint measurements were performed as described above.

\section{REPEATABILITY}

To assess short term repeatability, two sets of at least six measurements were performed about 1 minute apart in our lung function laboratory in preschool children referred to our centre with a history of either cough or wheeze. Short term repeatability was obtained for RintI and Rinte in two different groups of children. Rint measurements were performed as described above using the MicroRint (Micro Medical Ltd), a more recent version of the Microlab 4000. Rint repeatability was defined as two standard deviations of the paired differences between the two sets of measurements. ${ }^{6}{ }^{12}$ The intraclass correlation coefficient (ICC) was also calculated to measure Rint reproducibility. ${ }^{13}$

Long term repeatability was evaluated measuring Rinte during two different visits in preschool children referred to our centre with a history of either cough or wheeze. Children who had required a change in treatment between the two visits were excluded from calculations. The MicroRint was used for Rint measurements, and repeatability and reproducibility of the results were measured as above.

STATISTICAL ANALYSIS

The SPSS statistical package was used for the analysis. The Student's $t$ test was used for the comparison of means. Since the distribution of Rint differences between measurements with the cheeks supported and those with the cheeks not supported was not normal, a nonparametric test (Wilcoxon's matched pairs signed rank test) was used to assess the importance of supporting the cheeks in normal children. ${ }^{13}$ The Bland-Altman test ${ }^{12}{ }^{14}$ was also used to compare the measurements obtained with and without the cheeks supported and to evaluate the repeatability of the Rint measurements. Linear regression was used to study the correlation between Rint and the single variables. The validity of the regression models was checked by verifying the assumptions of linear regression. To examine the independent effects of age, height, and weight on Rint, multivariate analysis was performed using multiple regression. A two sided type 1 error of $<0.05$ was considered to be statistically significant.

\section{Results}

Questionnaires and informed consent forms were distributed to the families of the 536 children registered in the six kindergartens. A total of 436 questionnaires $(81.3 \%)$ were returned; 65 children $(14.9 \%)$ had a positive history of wheezing and were excluded from the study, 66 (15.1\%) did not undergo Rint measurements because they were not at school on the day of the test; 14 (4.6\% of those who underwent Rint measurements) were not able to perform the test; and seven of the normal children who performed the test were excluded from the analysis because they were non-white subjects. The final study population comprised 284 healthy preschool white children.

The characteristics of the study population are shown in table 1 . No significant differences were found between boys and girls in age, height, weight, nor in RintI or Rinte. The Student's $t$ test for paired samples showed no significant difference between RintI and RintE $(\mathrm{n}=277$, mean (SD) RintI $0.742(0.212) \mathrm{kPa} /$ 1.s, Rinte $0.725(0.220) \mathrm{kPa} / \mathrm{l} . \mathrm{s}, \mathrm{p}=0.127)$. Children exposed to passive smoking at home did not have higher respiratory resistance than children whose parents or relatives did not smoke (mean (SD) RintI $0.736(0.213) \mathrm{kPa} / \mathrm{l} . \mathrm{s}$ v $0.751(0.210) \mathrm{kPa} / 1 . \mathrm{s}, \mathrm{p}=0.539$; mean (SD) $\begin{array}{lllll}\text { RintE } & 0.728 & (0.224) \mathrm{kPa} / \mathrm{l} . \mathrm{s} & v & 0.722\end{array}$ $(0.217) \mathrm{kPa} / \mathrm{l} . \mathrm{s}, \mathrm{p}=0.803)$. Similarly, children whose first degree relatives had a positive history of asthma did not have higher respiratory resistance than children with a negative family history of asthma (mean (SD) RintI $0.732(0.210) \mathrm{kPa} / \mathrm{l} . \mathrm{s} v 0.746(0.212) \mathrm{kPa} / \mathrm{l} . \mathrm{s}$, $\mathrm{p}=0.757$; mean (SD) Rinte $0.716(0.275) \mathrm{kPa} /$ l.s $v 0.726(0.216) \mathrm{kPa} / 1 . \mathrm{s}, \mathrm{p}=0.841)$.

Univariate analysis showed a significant inverse linear correlation between Rint and age $\left(R^{2}=0.175, \mathrm{p}<0.001\right)$, Rint and height $\left(R^{2}=0.183\right.$, $\mathrm{p}<0.001$; fig $\left.1 \mathrm{~A}\right)$, and RintI and

Table 1 Mean (SD) characteristics of the study population

\begin{tabular}{lllll}
\hline & Total $(n=284)$ & Boys $(n=154)$ & Girls $(n=130)$ & $p$ Value \\
\hline Age (years) & $4.95(0.84)$ (range 3.0-6.4) & $4.99(0.86)$ & $4.92(0.81)$ & 0.480 \\
Height $(\mathrm{cm})$ & $111.77(6.58)$ (range 94-130) & $112.10(6.52)$ & $111.38(6.65)$ & 0.357 \\
Weight $(\mathrm{kg})$ & $19.90(3.49)$ (range 14-36) & $20.06(3.54)$ & $19.71(3.44)$ & 0.411 \\
RintI $(\mathrm{kPa} / \mathrm{l} . \mathrm{s})$ & $0.744(0.21)(\mathrm{n}=282)$ & $0.728(0.196)(\mathrm{n}=153)$ & $0.763(0.227)(\mathrm{n}=129)$ & 0.164 \\
RintE $(\mathrm{kPa} / \mathrm{l} . \mathrm{s})$ & $0.725(0.22)(\mathrm{n}=279)$ & $0.716(0.217)(\mathrm{n}=151)$ & $0.735(0.224)(\mathrm{n}=128)$ & 0.456
\end{tabular}

RintI, RintE = inspiratory and expiratory interrupter respiratory resistance. 


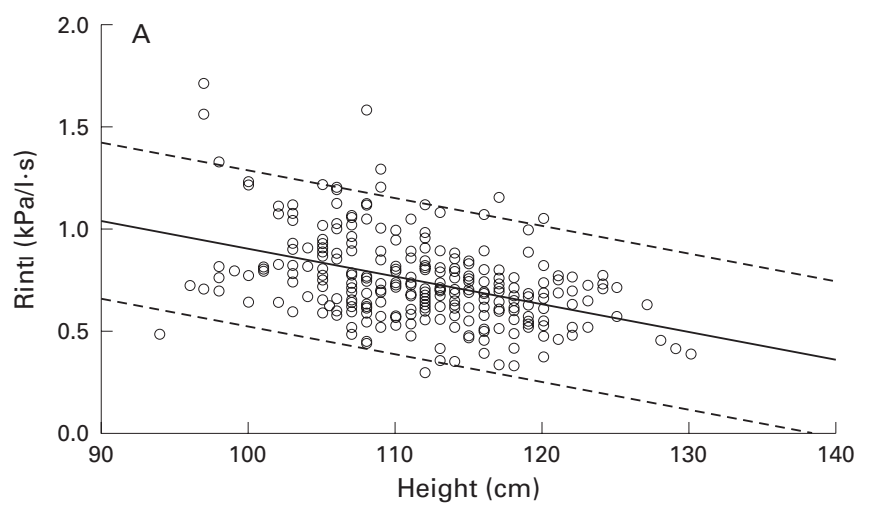

$\begin{array}{lcrrrrc} & \text { Coefficient (B) } & 95 \% \mathrm{Cl} \text { of B } & \text { SE of B } & \text { Beta } & p \\ \text { Height }(\mathrm{cm}) & -0.013710 & -0.01711 & -0.01031 & 0.0017 & -0.4282 & <0.001 \\ \text { Constant } & 2.276287 & 1.89521 & 2.65736 & 0.1936 & & <0.001 \\ R^{2}=0.183 & & & & & & \end{array}$

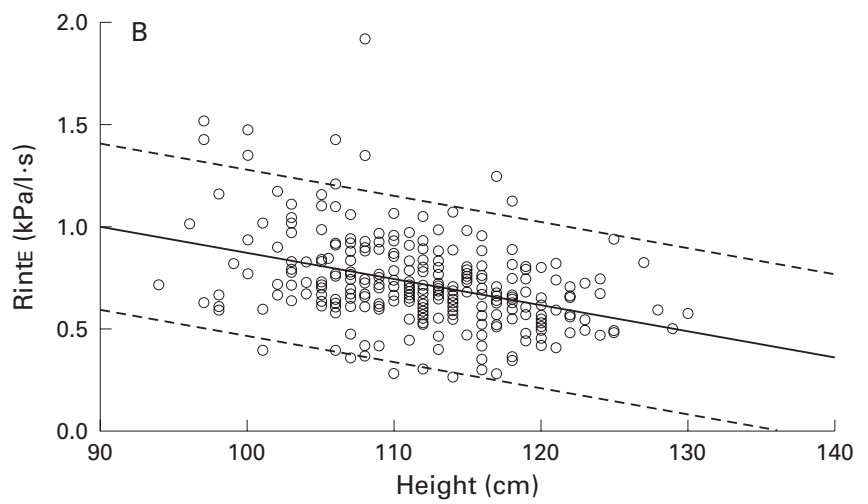

\begin{tabular}{lcrrrrc} 
& Coefficient (B) & \multicolumn{2}{c}{$95 \% \mathrm{Cl}$ of B } & SE of B & Beta & $p$ \\
Height $(\mathrm{cm})$ & -0.012538 & -0.01619 & -0.00888 & 0.0019 & -0.3761 & $<0.001$ \\
Constant & 2.126878 & 1.7176 & 2.53615 & 0.2079 & & $<0.001$
\end{tabular}

$R^{2}=0.141$

Figure 1 Linear regression of $(A)$ inspiratory interrupter resistance (RintI) and (B) expiratory interrupter resistance (RintE) versus height. The solid line indicates the regression line and dashed lines indicate the $95 \%$ prediction interval.

weight $\left(R^{2}=0.061, \mathrm{p}<0.001\right)$. Likewise, a significant inverse linear correlation in the univariate analysis was found between Rinte and age $\left(R^{2}=0.103, \mathrm{p}<0.001\right)$, Rinte and height $\left(R^{2}=0.141, \mathrm{p}<0.001 ;\right.$ fig $\left.1 \mathrm{~B}\right)$, and Rinte and weight $\left(R^{2}=0.058, \mathrm{p}<0.001\right)$. No additional polynomial effects were found for height, whereas significant effects of age squared and weight squared were found in the regression models including age and weight, respectively, as the independent variable.

Multiple regression with age, height, and weight as independent variables showed a significant and independent correlation of the three variables with RintI, although height showed the strongest correlation (age (years): coefficient -0.0573 (95\% CI -0.0975 to $0.0172)$, SE of coefficient 0.0204 , beta $-0.2285, \mathrm{p}=0.005$; height $(\mathrm{cm})$ : coefficient -0.0136 (95\% CI -0.0201 to -0.0071$)$, SE of coefficient 0.0033 , beta $-0.4249, \mathrm{p}<0.001$; weight $(\mathrm{kg})$ : coefficient $0.0132 \quad(95 \%$ CI 0.0033 to 0.0231 ), SE of coefficient 0.0050 , beta 0.2198, $\mathrm{p}=0.009$; constant: coefficient
2.2849 (95\% CI 1.7780 to 2.7918 ), SE of coefficient $\left.0.2575, \mathrm{p}<0.001 ; R^{2}=0.224\right)$. Only height was significantly correlated with Rinte in the multiple regression after adjusting for age and weight (age (years): coefficient -0.0230 (95\% CI -0.0674 to 0.0214 ), SE of coefficient 0.0226 , beta $0.0871, \mathrm{p}=0.309$; height $(\mathrm{cm})$ : coefficient $-0.0136(95 \%$ CI -0.0206 to $-0.0065)$, SE of coefficient 0.0036 , beta $-0.4067, \mathrm{p}<0.001$; weight $(\mathrm{kg})$ : coefficient 0.0079 ( $95 \%$ CI -0.0030 to 0.0187 ), SE of coefficient 0.0055 , beta $0.1252, p=0.154$; constant: coefficient 2.1989 (95\% CI 1.6459 to 2.7518), SE of coefficient $0.2809, \mathrm{p}<0.001$; $\left.R^{2}=0.151\right)$. Adding sex as an independent variable in the multiple model did not modify the results for either RintI or Rinte (data not shown). Including age squared and weight squared along with height, age, and weight as independent variables gave a model in which only height $(p<0.001)$ and age $(p=0.038)$ showed a significant linear correlation with RintI $\left(R^{2}=0.232\right)$, while height only $(\mathrm{p}=0.002)$ showed a significant linear correlation with Rinte $\left(R^{2}=0.162\right)$ after adjusting for the other covariates.

To assess the effect of upper airway compliance, Rint measurements were obtained both supporting and not supporting the cheeks in an additional group of children. The effect on Rint of supporting the cheeks was tested during inspiration in 29 children (17 boys and 12 girls of mean (SD) age 4.6 (1.0) years (range 2.7-6.3); height $109.0(8.3) \mathrm{cm}$ (range 90.0-125.0); weight 21.3 (4.5) kg (range 14.0-34.0)) and during expiration in 39 children (21 boys and 18 girls of mean (SD) age 4.8 (1.0) years (range 2.7-6.3); height 110.1 (8.0) cm (range 90.0-125.0); weight 21.0 (3.2) kg (range 16.2-29.0)). No significant difference was found between supporting and not supporting the cheeks in either RintI (median (range) $0.673(0.343-1.091) \mathrm{kPa} / \mathrm{l} . \mathrm{s}$ and $0.660(0.380-1.083) \mathrm{kPa} / \mathrm{l}$.s with cheeks supported and not supported, respectively, $\mathrm{p}=0.098$ ) or RintE (median (range) 0.702 $(0.350-1.100) \mathrm{kPa} / \mathrm{l} . \mathrm{s}$ and 0.713 (0.3271.090) $\mathrm{kPa} / \mathrm{l}$.s with cheeks supported and not supported, respectively, $\mathrm{p}=0.126)$. A BlandAltman plot of $\Delta$ RintI (fig $2 A$ ) and $\Delta$ Rinte (fig 2B) versus mean RintI and Rinte values (calculated as the mean of the two measurements obtained for each child supporting the cheeks and not supporting the cheeks) showed that $\Delta$ Rint values were distributed randomly with respect to mean Rint values.

Short term Rint repeatability (about 1 minute apart) was assessed for RintI in 50 children (27 boys and 23 girls of mean (SD) age 4.7 (1.0) years (range 2.8-7.6); height 108.4 (8.1) $\mathrm{cm}$ (range 90.0-122.0); weight 20.8 (5.4) $\mathrm{kg}$ (range 12.0-36.9) and for Rinte in 69 children ( 44 boys and 25 girls of mean (SD) age $4.7(0.8)$ years (range 2.6-6.5); height 108.2 (6.8) cm (range 87.0-123.0); weight 19.8 (4.1) kg (range 12.8-32.0). For Rint the mean (SD) of the first set of measurements was $0.845(0.217) \mathrm{kPa} / \mathrm{l}$.s while the mean (SD) of the second set of measurements was 0.825 $(0.219) \mathrm{kPa} / \mathrm{l}$.s (mean difference $0.020(95 \%$ 

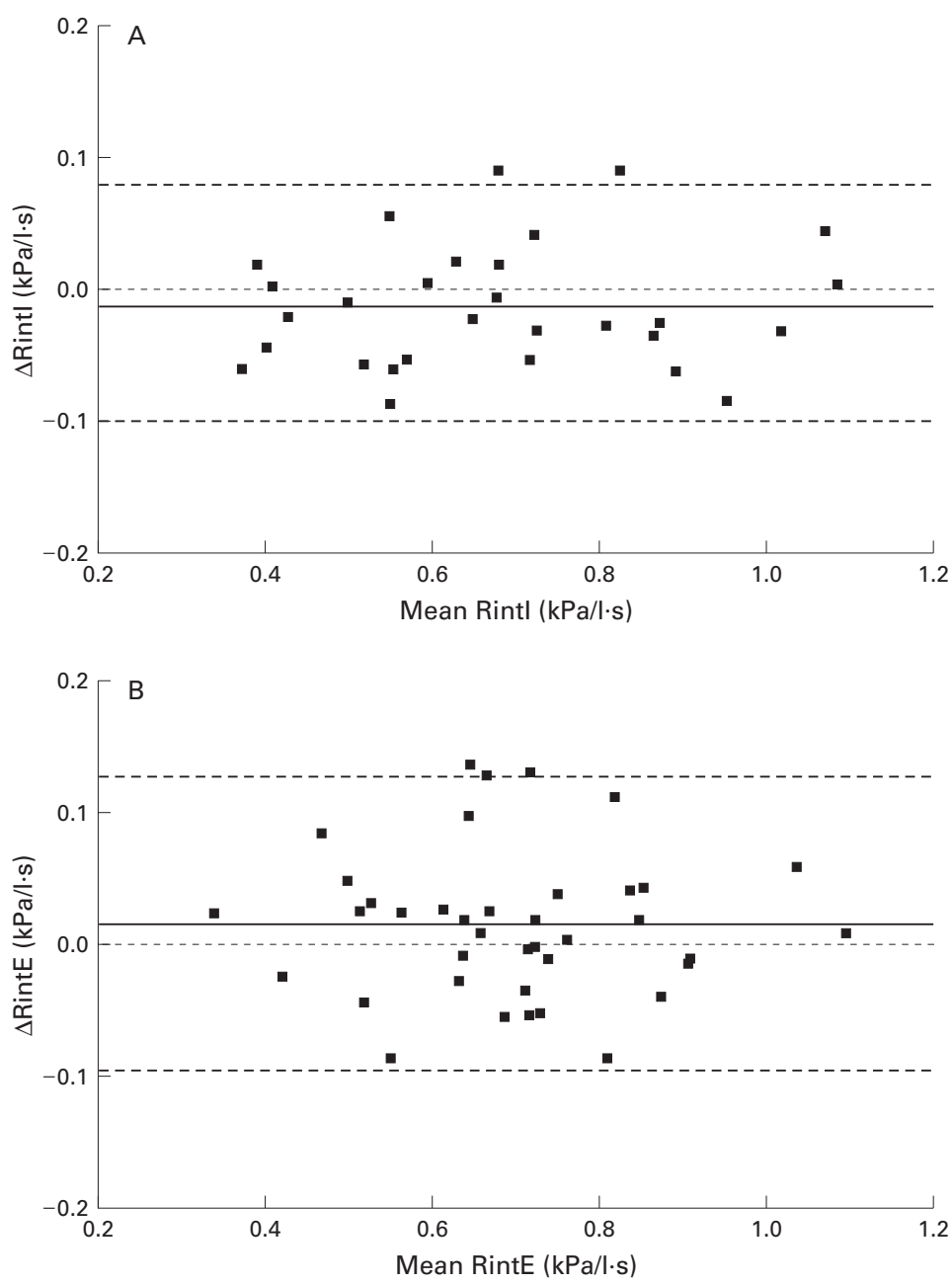

Figure 2 Bland-Altman plot of $(A)$ change in inspiratory interrupter resistance (ARintI) and (B) change in expiratory interrupter resistance (ARintE). $\Delta$ Rint was calculated as the difference between Rint cheeks supported and Rint cheeks not supported. The mean Rint values were calculated as the mean of the two measurements obtained for each child supporting the cheeks and not supporting the cheeks. The solid line indicates mean $\Delta R i n t$ and the dashed lines indicate the $95 \%$ limits of agreement between the two sets of measurements (URintI -0.104 to $0.080 \mathrm{kPa} / \mathrm{l} . \mathrm{s} ; \Delta$ Rinte -0.094 to $0.126 \mathrm{kPa} / \mathrm{l} . \mathrm{s}$ ).

CI -0.008 to 0.049$) \mathrm{kPa} / \mathrm{l} . \mathrm{s}, \mathrm{p}=0.161)$. For RintE the mean (SD) of the first set of measurements was $1.042(0.303) \mathrm{kPa} / \mathrm{l}$.s while the mean $(\mathrm{SD})$ of the second set of measurements was $1.036(0.291) \mathrm{kPa} / \mathrm{l} . \mathrm{s}$ (mean difference 0.007 (95\% CI -0.022 to 0.036$) \mathrm{kPa} / \mathrm{l} . \mathrm{s}$, $\mathrm{p}=0.649)$. Short term repeatability was $0.202 \mathrm{kPa} / 1$.s for RintI and $0.242 \mathrm{kPa} / 1$.s for RintE. The ICC was 0.89 for RintI and 0.87 for RintE. A Bland-Altman plot showed no relation between the difference and the mean of the two sets of measurements for RintI or for RintE (data not shown).

Long term repeatability was assessed for RintE in 26 children (17 boys and nine girls of mean (SD) age $4.3(0.8)$ years (range 3.1-5.8); height 104.5 (5.5) cm (range 94.0-114.0); weight 18.1 (2.3) $\mathrm{kg}$ (range 15.0-24.0)). The mean (SD) time between the two sets of measurements was 2.5 (1.5) months (range 1.924.9 weeks). The mean (SD) of the first set of measurements was $1.094(0.247) \mathrm{kPa} / \mathrm{l}$.s while the mean (SD) of the second set of measurements was $1.060(0.268) \mathrm{kPa} / \mathrm{l} . \mathrm{s}$ (mean difference $0.034(95 \%$ CI -0.008 to 0.076$)$, $\mathrm{p}=0.112$ ). Long term Rinte repeatability was $0.208 \mathrm{kPa} / 1$.s. The ICC was 0.91 . As for short term repeatability, a Bland-Altman plot showed no relation between the difference and the mean of the two sets of measurements (data not shown).

\section{Discussion}

This study has shown that the interrupter technique can easily produce measurements of lung function in preschool children using a commercially available portable device. The success rate of $95.4 \%$ in children aged 3.0-6.4 years shows that this technique has the potential to fill an important gap in our present ability to measure lung function in children. The data presented here can also serve as reference data for white children.

The theory behind the interrupter technique is based on instantaneous airway occlusion causing an instantaneous cessation of flow. ${ }^{15}$ Under these circumstances, the instantaneous change in pressure of the airway opening represents the resistive pressure drop across the conducting airways at the moment of airway occlusion. This resistive pressure drop divided by the flow occurring immediately before the occlusion yields the resistance of the constructing airways (Raw). Two major assumptions are involved: (1) instantaneous airway occlusion and (2) instantaneous equilibration of alveolar and airway opening pressures.

Bates and coworkers ${ }^{16}{ }^{17}$ have shown that, although instantaneous occlusion is not physically possible, in practice accurate measurements of Raw can be obtained with a valve that closes in <10-20 ms. They have further shown ${ }^{18} 19$ that, while upper airway compliance can delay equilibration between alveolar and airway opening pressures, the errors that this introduces may be acceptable under usual clinical situations. In the present study the use of a valve that closes in approximately $10 \mathrm{~ms}$ and the fact that no systematic differences were seen with and without the cheeks supported give confidence in the technical reliability of the measurements reported. In a study by Oswald-Mammosser and colleagues, ${ }^{5}$ significantly lower Rint values were obtained when cheeks were not supported than when they were supported, even in normal subjects. However, the different methods used by these authors (especially the different method of back extrapolation of mouth pressure from about $40 \mathrm{~ms}$ and $20 \mathrm{~ms}$ to $5 \mathrm{~ms}$ after beginning of closure) might be responsible for the discrepancies between their results and those found in our investigation.

Our data do not show any significant differences between inspiratory and expiratory resistance. This is in contrast with the studies by Carter $e t a l^{\beta}$ and Oswald-Mammosser $e t a \bar{l}^{\bar{p}}$ who found that expiratory resistance was higher than inspiratory resistance. Our finding is somewhat surprising given the well known differences in transmural pressures which tend to increase airway calibre during inspiration and decrease airway calibre during expiration. There was a tendency in both boys and girls for RintI to be greater than RintE. One possible 
explanation for this finding could be a difference in flow profiles between inspiration and expiration. As Raw is flow-dependent, if higher flows were seen during inspiration than during expiration, this might counteract any difference in airway calibre expected throughout the respiratory cycle. In addition, as the Rint measurements were made at peak flow during inspiration and expiration, it is possible that the volumes at which these measurements were made differ between inspiration and expiration. Young children breathing through an unfamiliar device may be expected to have a degree of active expiration. Under these circumstances, peak expiratory flow would be expected to occur at a higher lung volume than peak inspiratory flow. Despite the lack of a statistically significant difference between RintI and Rinte, it would seem prudent not to mix these measurements but to report each separately.

The statistical models used in this study showed that height was the best predictor of Rint. Sex was not a significant predictor. In older children height and sex are the two variables routinely used to standardise measurements of lung function. Our data would suggest that a prediction equation based on height should be sufficient for clinical use. We cannot exclude the need for separate prediction equations for boys and girls. However, these would need to be based on a substantially larger population than the one we studied.

We have shown short term and long term repeatability of Rint measurements. Although short term repeatability using the standard interrupter method has been reported by one paper, ${ }^{6}$ no studies have so far assessed long term repeatability of Rint measurement. The overall short term repeatability reported for Rinte by Bridge and coworkers ${ }^{6}$ in 120 preschool children with and without a history of respiratory symptoms $(0.17 \mathrm{kPa} / \mathrm{l} . \mathrm{s})$ is slightly lower than that found in our study $(0.24 \mathrm{kPa} / \mathrm{l} . \mathrm{s})$. Overall short term and long term repeatability was similar in the present study $(0.20 \mathrm{kPa} / 1 . \mathrm{s}$ for short term RintI, $0.24 \mathrm{kPa} / 1$.s for short term Rinte, $0.21 \mathrm{kPa} / 1$.s for long term RintE). Furthermore, the intraclass correlation coefficient (ICC), an estimate of measurement reproducibility, showed good and consistent values both short term and long term ( 0.89 for short term Rint, 0.87 for short term RintE, 0.91 for long term RintE). These findings give confidence in the repeatability and reproducibility of Rint measurements even after several weeks.

Two points about the repeatability studies need to be addressed. Our repeatability data have been collected in preschool children referred to our centre because of a history of cough or wheeze. Since a recent study has suggested that older children with asthma, wheeze, or bronchial hyperreactivity have a greater variability in lung function than healthy children, ${ }^{20}$ the variability in Rint found in children with a history of cough or wheeze would be expected to be lower or similar, but not higher, in healthy children. It should also be pointed out that the device used for the repeatability data (MicroRint) was different from that used for collecting the reference data in healthy children (MicroLab 4000). The MicroRint is a more recent version of the MicroLab 4000 released by the same company. We have previously found ${ }^{21}$ that the difference between the measurements made with the two devices is not higher than the intrasubject repeatability using the MicroLab $4000 .^{6}$

In summary, the data from this study show that technically acceptable measurements of interrupter resistance can be obtained in preschool children, with $95.4 \%$ of children aged 3.0-6.4 years being able to perform the test using a commercially available portable device. Reference equations based on the height of the children are presented.

We are grateful to Mr Luigi Sgarra for his technical assistance and to Professor Vieri Boddi, University of Florence for his comments on the statistical analysis. This work was supported by the University of Florence and GRIAP (Gruppo di Ricerca in Immunologia e Allergologia Pediatrica).

1 Chowienczyk PJ, Lawson CP, Lane S, et al. A flow interrupion device for measurement of airway resistance. Eur Respir f 1991;4:623-8.

2 Phagoo SB, Watson RA, Pride NB, et al. Accuracy and sensitivity of the interrupter technique for measuring the response to bronchial challenge in normal subjects. Eur Respir F 1993;6:996-1003.

3 Carter ER, Stecenko AA, Pollock BH, et al. Evaluation of the interrupter technique for the use of assessing airway obstruction in children. Pediatr Pulmonol 1994;17:211-7.

4 Phagoo SB, Wilson NM, Silverman M. Evaluation of a new interrupter device for measuring bronchial responsiveness and the response to bronchodilator in 3 year old children. Eur Respir f 1996;9:1374-80.

5 Oswald-Mammosser M, Llerena C, Speich JP, et al. Measurements of respiratory system resistance by the interrupter technique in healthy and asthmatic children. Pediatr Pulmonol 1997;24:78-85.

6 Bridge PD, Ranganathan SA, McKenzie SA. Measurement of airway resistance using the interrupter technique in preof airway resistance using the interrupter technique in pre-
school children in the ambulatory setting. Eur Respir $f$ 1999;13:792-6.

7 Klug B, Bisgaard H. Specific airway resistance, interrupter resistance, and respiratory impedance in healthy children aged 2-7 years. Pediatr Pulmonol 1998;25:322-31

8 Vooren PH, van Zomeren BC. Reference values of total respiratory resistance, determined with the "opening" interruption technique. Eur Respir $\mathcal{F}$ 1989;2:966-71.

9 Van Altena R, Gimeno F. Respiratory resistance measured by flow-interruption in a normal population. Respiration 1994;61:249-54.

10 Phagoo SB, Wilson NM, Silverman M. Evaluation of the interrupter technique for measuring change in airway resistance in 5-year-old asthmatic children. Pediatr Pulmonol 1995;20:387-95.

11 Bridge PD, Lee H, Silverman M. A portable device based on the interrupter technique to measure bronchodilator response in schoolchildren. Eur Respir f 1996;9:1368-73.

12 Bland JM, Altman DG. Statistical methods for assessing agreement between two methods of clinical measurement. anreement between two $1986 ; 1: 307-10$.

13 Armitage P, Berry G. Statistical methods in medical research. 3rd ed. Oxford: Blackwell Scientific Publications, 1994.

14 Bland JM, Altman DG. Comparing methods of measurement: why plotting difference against standard method is misleading. Lancet 1995;346:1085-7.

15 Jackson AC, Milhorn HT, Norman JR. A reevaluation of the interrupter technique for airway resistance measurement. $\mathcal{F}$ Appl Physiol 1974;36:264-8.

16 Bates JHT, Hunter IW, Sly PD, et al. Effect of valve closure time on the determination of respiratory resistance by flow interruption. Med Biol Eng Comput 1987;25:136-40.

17 Sly PD, Bates JHT, Milic-Emili J. Measurement of respiratory mechanics using the Siemens Servo Ventilator 900C. Pediatr Pulmonol 1987;3:400-5.

18 Bates JHT, Sly PD, Kochi T, et al. The effect of proximal compliance on interrupter measurements of resistance. Compliance on interrupter mest

19 Bates JHT, Sly PD, Okubo S. General method for describing and extrapolating monotonic transients and its application to respiratory mechanics. Med Biol Eng Comput 1987;25:131-5.

20 Studnicka M, Frischer T, Neumann M. Determinants of reproducibility of lung function tests in children aged 7 to 10 years. Pediatr Pulmonol 1998;25:238-43.

21 Lombardi E, Novembre E, Bridge PD, et al. Comparison of two devices for assessment of interrupter resistance in children. Eur Respir F 1999;14(Suppl 30):44s. 